\title{
Effects of a single session of transcranial direct current stimulation on static balance in a patient with hemiparesis: a case study
}

\author{
Arislander Jonathan Lopes Dumont ${ }^{1}$, Maria Carolina Araujo ${ }^{1)}$, \\ Roberta Delasta Lazzari ${ }^{1)}$, Cibele Almeida Santos ${ }^{1)}$, Debora Bachin Carvalho ${ }^{2)}$, \\ Renata Calhes Franco de Moura ${ }^{3)}$, Luiz Alfredo Braun Ferreira ${ }^{3,4)}$, Manuela Galli ${ }^{5)}$, \\ Claudia Santos Oliveira ${ }^{6 *}$ \\ 1) Master's Program in Rehabilitation Sciences, University Nove de Julho, Brazil \\ 2) Department of Physiotherapy, University Nove de Julho, Brazil \\ 3) Doctoral Program in Rehabilitation Sciences, University Nove de Julho, Brazil \\ 4) Guairacá College, Student Doctoral Program in Rehabilitation Sciences, University Nove, Brazil \\ 5) Dipartimento di Bioingegneria, Politecnico di Milano, Italy \\ 6) Master's and Doctoral Programs in Rehabilitation Sciences, University Nove Julho, Brazil
}

\begin{abstract}
Purpose] Cerebrovascular accident (stroke) is characterized by an abrupt onset of focal or global neurological signs and symptoms. Asymmetry of the limbs is common following a stroke due to hemiplegia or hemiparesis. [Subject and Methods] A male patient having suffered an ischemic stroke was initially evaluated using the Timed Up-and-Go Test and the Six-Minute Walk Test. Static balance was evaluated using a force plate (Kistler model 9286BA) for the stabilometry analysis of center of pressure (COP) sway. The data were interpreted using the SWAY software program (BTS Engineering) synchronized with the SMART-D $140^{\circledR}$ system. Anodal transcranial direct current stimulation (tDCS; $2 \mathrm{~mA}$ ) was applied over the primary motor cortex for 20 minutes during gait training on a treadmill. [Results] Under the condition of eyes open, reductions were found in anteroposterior sway (6.18\%), trace length (3.3\%) and sway velocity (3.3\%) immediately following tDCS. [Conclusion] A single session of anodal tDCS combined with treadmill training had a positive effect on the static balance of a subject with chronic hemiparesis stemming from a stroke.

Key words: Hemiparesis, Transcranial direct current stimulation, Balance
\end{abstract}

(This article was submitted Sep. 19, 2014, and was accepted Oct. 24, 2014)

\section{INTRODUCTION}

Cerebrovascular accident (stroke) is categorized as either hemorrhagic or ischemic and is characterized by an abrupt onset of focal or global neurological signs and symptoms ${ }^{1)}$. The main risk factors of a stroke are atherosclerosis, thrombosis, embolism, arterial hypertension, the malformation of a blood vessel and heart disease ${ }^{2}$. A stroke can occur when blood flow to an area of the central nervous system is interrupted. The consequences of a stroke depend on the anatomic location of the brain lesion ${ }^{2,3)}$.

Stroke is one of the main causes of death and disability. Annually, approximately 15 million individuals throughout the world suffer a stroke, five million of whom die and 10 million survive. Stroke survivors experience persistent

\section{*Corresponding author. Claudia Santos Oliveira (E-mail:} csantos@uninove.br)

C2015 The Society of Physical Therapy Science. Published by IPEC Inc. This is an open-access article distributed under the terms of the Creative Commons Attribution Non-Commercial No Derivatives (by-ncnd) License $<$ http://creativecommons.org/licenses/by-nc-nd/3.0/> . neurological disorders, that affect functional capacity ${ }^{4}$. Asymmetry of the limb function is common following a stroke, due to hemiplegia or hemiparesis caused by upper motor neuron syndrome, which results in reductions in both muscle strength and motor control as well as spasticity, hyperreflexia, co-contraction and spastic dystonia in the affected limbs. These conditions result in an abnormal gait pattern, a loss of balance and inadequate posture ${ }^{5)}$.

The literature describes different forms of therapy for improving the balance and posture of stroke survivors. PradoMedeiros et al. ${ }^{6}$, reported an improvement in the balance of stroke survivors after treadmill training with partial weight support combined with functional electrical stimulation. Min Kyun Sohn et al. ${ }^{7)}$ reported a significant improvement in the postural stability of patients treated with transcranial direct current stimulation (tDCS).

Motor training can be combined with noninvasive brain stimulation techniques to optimize the functional outcome through the potentiation of neuroplastic changes ${ }^{8)}$. Thus, tDCS has become a topic of interest among researchers. This safe, inexpensive form of brain stimulation causes lasting changes in the excitability of the motor cortex in both animals and humans. The method involves the administration 
of a monophasic, low-intensity, electrical current to the scalp using silicone-sponge surface electrodes moistened with saline solution. The effects of tDCS are achieved by the movement of electrons due to the difference in electrical charge. The anodal electrode has a positive current and the cathode has a negative current. The electrons flow from the negative to the positive pole, causing different effects on biological tissues. While most of the current is dissipated among the overlying tissues, enough reaches the primary motor cortex to alter the membrane potential of local cells ${ }^{9,10)}$.

Although most studies of tDCS have addressed upper limb function ${ }^{11)}$, few investigations have addressed the positive effects on the affected lower limb of stroke survivors. Min Kyun Sohn et al. ${ }^{7}$ reported the improved balance of individuals with sub-acute stroke improved following the administration of tDCS. However, no previous study has investigated the use of this method on individuals with chronic manifestations of a stroke.

The aim of the present study was to determine the effects of tDCS combined with treadmill training on the static balance of an individual with chronic hemiparesis stemming from a stroke.

\section{SUBJECTS AND METHODS}

This study was carried out in compliance with the regulating guidelines and norms regulating research involving human subjects stipulated by the Brazilian National Health Board in October 1996, and it received approval from the Human Research Ethics Committee of University (Brazil) under process number 575.519. The patient signed a statement of informed consent declaring that he was aware that the procedure to which he would receive was experimental and free of charge. The study was conducted at the Human Movement Analysis Laboratory of the Postgraduate Program in Rehabilitation Science of the University Nove de Julho, which had the necessary infrastructure, academic and professional personnel and institutional support to ensure the safe execution of the study.

The participant was a male patient aged 66 years (weight: $72 \mathrm{~kg}$, height: $1.68 \mathrm{~m}$ ) with chronic hemiparesis stemming from an ischemic stroke four years earlier. The patient was given an explanation of the procedures; the identification chart was filled out and anthropometric measures (body mass, height and body mass index) were determined. The patient performed the Timed Up-and-Go test and SixMinute Walk test to determine eligibility for the study: The Timed Up-and-Go Test is widely used in the assessment of functional mobility and dynamic balance and measures the time (in seconds) necessary to stand up from a chair with arm rests, walk three meters, turn around, walk back to the chair and sit down again ${ }^{12,13)}$. The Six-Minute Walk Test measures the distance walked in six minutes walking at a self-selected pace, which may vary and may include rest intervals. The patient performed the test twice on a 30-meter track. The first test was used in familiarize the patient with the procedure and the result of the second test was used in the analysis ${ }^{14,15)}$.

Stabilometric analysis was performed for the evaluation of static balance before and after treatment. For this, a force

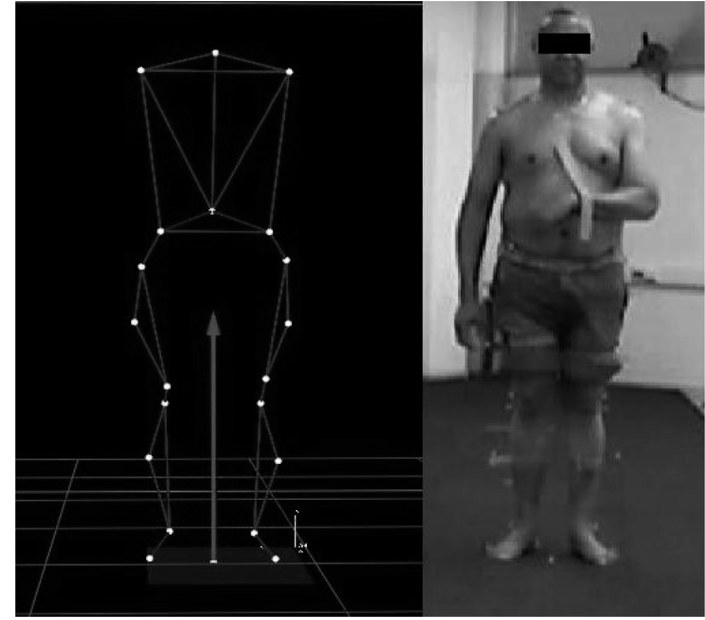

Fig. 1. Three-dimensional stabilometric analysis (Kistler force plate, model 9286B), with data interpreted using SWAY software program (BTS 161 Engineering) synchronized to SMART-D $140^{\circledR}$ system

plate (Kistler model 9286BA) measuring $40 \times 60 \mathrm{~cm}$ was used to record of center of pressure (COP) sway, which was acquisition captured by four piezoelectric sensors positioned at the extremities of the force plate at a frequency of $50 \mathrm{hz}$. The data were recorded and interpreted using the SWAY software program (BTS 161 Engineering) integrated and synchronized with the SMART-D $140^{\circledR}$ system. The patient was instructed to quiet stand barefoot in quiet standing on the force plate with an unrestricted foot base, the heels aligned and look at a fixed on a point marked at a distance of one meter at the height of the glabellum. Measurements of 45 seconds were taken three times with the eyes open and the eyes closed. Images in Fig. 1 illustrate the three-dimensional evaluation.

tDCS was administered using a transcranial stimulation device (Trans Cranial Technologies, USA) with two sponge (non-metallic) surface electrodes measuring $5 \times 5 \mathrm{~cm}$ moistened with saline solution. The anode was positioned over the primary motor cortex of the injured brain hemisphere, following the international 10-20 electroencephalogram system, and the cathode was positioned over the supraorbital region on the contralateral side ${ }^{16}$. Stimulus was delivered using a current of $2 \mathrm{~mA}$ was run for 20 minutes. The device has a knob that allows the operator to control the intensity of the current, which was gradually increased in the first minute until it reached $2 \mathrm{~mA}$, so that the patient would not feel discomfort and gradually diminished in the last minute to avoid the abrupt interruption of the current.

A treadmill (Imbramed, model Milenium ATL, RS, Brazil) was used for gait training during the 20 minutes of tDCS. The training velocity was established based on the result of the Six-Minute Walk Test, during which the patient travelled 218 meters. Training began at $60 \%$ average walking speed of the test, which corresponded to $1.3 \mathrm{~km} / \mathrm{h}$. After five minutes, the velocity was increased to $80 \%$ average walking speed of the test, corresponding to $1.75 \mathrm{~km} / \mathrm{h}$, and was maintained until the final two minutes, when the velocity was reduced to 
Table 1. Mean \pm standard deviation of stabilometric values of a stroke survivor standing with the eyes open and closed before and after transcranial direct current stimulation

\begin{tabular}{lcccc}
\hline & \multicolumn{2}{c}{ Eyes open } & \multicolumn{2}{c}{ Eyes closed } \\
\cline { 2 - 5 } & \multicolumn{1}{c}{ Pre } & \multicolumn{1}{c}{ Post } & Pre & Post \\
\hline Maximum COP sway (mm) & $12.80 \pm 0.83$ & $12.92 \pm 2.59$ & $11.31 \pm 3.41$ & $13.32 \pm 1.37$ \\
Minimum COP sway (mm) & $0.18 \pm 0.09$ & $0.23 \pm 0.24$ & $0.22 \pm 0.14$ & $0.21 \pm 0.13$ \\
Anteroposterior (mm) & $16.34 \pm 1.08$ & $15.33 \pm 3.05$ & $12.67 \pm 2.56$ & $13.30 \pm 3.79$ \\
Mediolateral COP sway (mm) & $19.43 \pm 1.90$ & $20.06 \pm 3.74$ & $17.41 \pm 5.73$ & $20.86 \pm 1.55$ \\
Trace length (mm) & $411.10 \pm 28.33$ & $397.76 \pm 25.65$ & $409.06 \pm 26.66$ & $434.61 \pm 36.13$ \\
Speed (mm/s) & $8.98 \pm 0.70$ & $8.69 \pm 0.56$ & $8.89 \pm 0.56$ & $9.49 \pm 0.83$ \\
Equivalent area (mm) & $1,015.6 \pm 206.2$ & $1,121.6 \pm 223.2$ & $1,080.4 \pm 264.4$ & $1,299.0 \pm 333.8$ \\
\hline
\end{tabular}

$1.3 \mathrm{~km} / \mathrm{h}$ to avoid an abrupt interruption of physical effort. At the end of the session, the distance travelled was recorded (826 meters). Heart rate and blood pressure were monitored to avoid an overload of the cardiovascular system.

\section{RESULTS}

As shown in Table 1, reductions were found in anteroposterior COP (6.18\%) sway, trace length (3.3\%) and sway velocity $(3.3 \%)$ immediately following tDCS when the patient stood with the eyes open. Increases were found in the values of all other variables analyzed in both the eyes open and eyes closed conditions.

\section{DISCUSSION}

Transcranial direct current stimulation has been widely employed in the treatment of stroke survivors and patients with Parkinson's disease, depression and pain. In the present study, the patient had chronic hemiparesis stemming from a stroke with a four-year history, and was evaluated after a single session of anodal tDCS combined with treadmill training. According to Park et al. ${ }^{17)}$, an approximately twofold increase in body sway is found among stroke survivors in comparison to healthy individuals. This occurs due to asymmetry, as well as difficulties in distributing body weight evenly between the lower limbs, and the ability to move the center of gravity to the paretic side. In the present study, reductions in anteroposterior sway, trace length and sway velocity occurred following tDCS. According to Grecco et al. ${ }^{18)}$, the effects of tDCS depend on the location and polarity of the electrodes, and the intensity of the current used to enhance the excitability of the primary motor cortex. In a pilot study, Tahtis et al. ${ }^{19)}$ found improvements in the dynamic balance of sub-acute stroke survivors following a single session of bi-cephalic tDCS with the anodal electrode placed on the scalp over the ispilateral lower limb motor cortex and the cathode placed over the contralateral lower limb motor cortex. Duarte et al. ${ }^{20)}$ performed anodal tDCS on children with cerebral palsy $(1 \mathrm{~mA})$ in five weekly sessions and found that stimulation potentiated treadmill training, with improvements in both dynamic and static balance in comparison to a group submitted to placebo tDCS.

Studies addressing the effects of tDCS on individuals with chronic hemiparesis have mainly focused on upper limb function ${ }^{18)}$ but recent investigations have addressed the effects on the lower limbs. Satoshi Tanaka et al. ${ }^{21)}$ report an improvement in the muscle strength of the affected lower limb of individuals with chronic hemiparesis stemming from a stroke immediately following a single session of anodal tDCS over the primary motor cortex on the side of the brain lesion. In another study involving individuals with chronic hemiparesis stemming from a stroke, three sessions of anodal tDCS over the damaged motor cortex using a specific strategy targeting the ankle of the affected limb led to improvements in dorsiflexion and plantar flexion, which are fundamental to postural control and balance ${ }^{8)}$. In the present case study, a single session of anodal tDCS over the motor cortex on the side of the brain lesion combined with treadmill training led to improvements in the static balance of the patient who had hemiparesis stemming from a stroke. Further studies with larger samples are needed to determine the number of sessions and application time of anodal tDCS, which are necessary to achieve gains in static and dynamic balance among patients with chronic hemiparesis.

\section{ACKNOWLEDGEMENTS}

The authors are grateful to the following Brazilian governmental agencies: The National Council for Scientific and Technological Development (CNPq), Coordination for the Advancement of Higher Education Personnel (CAPES) and State of São Paulo Research Assistance Foundation (FAPESP-2013/22625-2).

\section{REFERENCES}

1) Iwabe C, da Rocha Diz MA, Barudy DP: Análise cinemática da marcha em indivíduos com Acidente Vascular Encefálico. Rev Neurocienc, 2008, 16: 292-296.

2) Smith L, Weiss E, Lehmkuhl D: Cinesiologia Clínica de Brunnstrom. $5^{\mathrm{a}}$ edição. Editora Manole, São Paulo, 1997.

3) Contran RS, Kumar V, Robbins SL: Patologia Estrutural e Funcional. $5^{a}$ edição, Editora Guarabara Koogan, Rio de Janeiro, 1996.

4) Thijssen DH, Paulus R, van Uden CJ, et al.: Decreased energy cost and improved gait pattern using a new orthosis in persons with long-term stroke. Arch Phys Med Rehabil, 2007, 88: 181-186. [Medline] [CrossRef]

5) Chen $\mathrm{CC}$, Hong WH, Wang CM, et al.: Kinematic features of rear-foot motion using anterior and posterior ankle-foot orthoses in stroke patients with hemiplegic gait. Arch Phys Med Rehabil, 2010, 91: 1862-1868. [Medline] [CrossRef]

6) Prado-Medeiros CL, Sousa CO, Souza AS, et al.: Effects of the addition 
of functional electrical stimulation to ground level gait training with body weight support after chronic stroke. Rev Bras Fisioter, 2011, 15: 436-444. [Medline] [CrossRef]

7) Sohn MK, Jee SJ, Kim YW: Effect of transcranial direct current stimula tion on postural stability and lower extremity strength in hemiplegic stroke patients. Ann Rehabil Med, 2013, 37: 759-765. [Medline] [CrossRef]

8) Stagg CJ, Bachtiar V, O'Shea J, et al.: Cortical activation changes underlying stimulation-induced behavioural gains in chronic stroke. Brain, 2012 135: 276-284. [Medline] [CrossRef]

9) Miranda PC, Lomarev M, Hallett M: Modeling the current distribution during transcranial direct current stimulation. Clin Neurophysiol, 2006, 117: 1623-1629. [Medline] [CrossRef]

10) Wagner T, Fregni F, Fecteau $S$, et al.: Transcranial direct current stimulation: a computer-based human model study. Neuroimage, 2007, 35: 1113 1124. [Medline] [CrossRef]

11) Hummel F, Celnik P, Giraux P, et al.: Effects of non-invasive cortica stimulation on skilled motor function in chronic stroke. Brain, 2005, 128 : 490-499. [Medline] [CrossRef]

12) Williams EN, Carroll SG, Reddihough DS, et al.: Investigation of the timed 'up \& go' test in children. Dev Med Child Neurol, 2005, 47: 518-524. [Medline] [CrossRef]

13) Podsiadlo D, Richardson S: The timed "Up \& Go": a test of basic functional mobility for frail elderly persons. J Am Geriatr Soc, 1991, 39: 142-148. [Medline]

14) ATS Committee on Proficiency Standards for Clinical Pulmonary Function Laboratories: ATS statement: guidelines for the six-minute walk test.
Am J Respir Crit Care Med, 2002, 166: 111-117. [Medline] [CrossRef]

15) Maher CA, Williams MT, Olds TS: The six-minute walk test for children with cerebral palsy. Int J Rehabil Res, 2008, 31: 185-188. [Medline] [CrossRef]

16) Homan RW, Herman J, Purdy P: Cerebral location of international 10-20 system electrode placement. Electroencephalogr Clin Neurophysiol, 1987, 66: 376-382. [Medline] [CrossRef]

17) Park SW, Lee KJ, Shin DC, et al.: The effect of underwater gait training on balance ability of stroke patients. J Phys Ther Sci, 2014, 26: 899-903. [Medline] [CrossRef]

18) Grecco LA, Duarte NA, de Mendonça ME, et al.: Effect of transcranial direct current stimulation combined with gait and mobility training on functionality in children with cerebral palsy: study protocol for a doubleblind randomized controlled clinical trial. BMC Pediatr, 2013, 13: 168. [Medline] [CrossRef]

19) Tahtis V, Kaski D, Seemungal BM: The effect of single session bi-cephalic transcranial direct current stimulation on gait performance in sub-acute stroke: a pilot study. Restor Neurol Neurosci, 2014, 32: 527-532. [Medline]

20) Duarte NA, Grecco LA, Galli M, et al.: Effect of transcranial direct-current stimulation combined with treadmill training on balance and functional performance in children with cerebral palsy: a double-blind randomized controlled trial. PLoS ONE, 2014, 9: e105777. [Medline] [CrossRef]

21) Tanaka S, Takeda K, Otaka Y, et al.: Single session of transcranial direct current stimulation transiently increases knee extensor force in patients with hemiparetic stroke. Neurorehabil Neural Repair, 2011, 25: 565-569. [Medline] [CrossRef] 